\title{
Steroid Therapy in the Management of Sudden Sensorineural Hearing Loss: A Nonrandomized Clinical Trial
}

\author{
Gowri Swaminathan ${ }^{1 \oplus}$ Ravi Ramalingam ${ }^{1} \quad$ Ramalingam Kombupalayam Kumarappa Gounder $^{1}$ \\ ${ }^{1}$ Department of Otology, KKR ENT Hospital and Research Institute, \\ Address for correspondence Gowri Swaminathan, DNB (ENT), \\ Chennai, Tamil Nadu, India \\ KKR ENT, Hospital and Research Institute, No. 274, Poonamallee \\ High Road, Kilpauk, Chennai 600010, Tamil Nadu, India \\ (e-mail: drgowrinsn@gmail.com).
}

Ann Otol Neurotol:2019;2:59-65

Abstract

Keywords
- hearing loss
- intratympanic steroids
- sudden sensorineural
hearing loss

Objective The aim of this study was to compare the effectiveness of intratympanic (IT) steroid therapy and combined intravenous-cum-intratympanic (IVIT) steroid therapy in the management of sudden sensorineural hearing loss (SSNHL).

Study Design This was a nonrandomized clinical trial.

Setting Tertiary referral center.

Patients Forty-four patients, who presented to the outpatient department or the emergency room and those who fulfilled the inclusion criteria, were enrolled in this study. The patients were put into two groups: Group IT-that received intratympanic steroid therapy alone and Group IVIT-that received intratympanic as well as intravenous steroid therapies.

Intervention Therapeutic-in the form of IVIT steroid therapy.

Main Outcome Measure Impact of the steroid therapy in patients with SSNHL was measured objectively with the help of pure tone audiometry (PTA). The improvement in hearing was assessed in terms of decibels gained after the intervention in both the groups.

Results The mean improvement in PTA after 3 months in Group IT was 19.78 $( \pm 18.918) \mathrm{dB}$, whereas the mean improvement after 3 months in Group IVIT was 22.29 $( \pm 16.147) \mathrm{dB}$, statistically showing no significant difference between the groups.

Conclusion The authors recommend the use of IT steroid therapy alone in the management of SSNHL.

\section{Introduction}

Sudden sensorineural hearing loss (SSNHL), which was first described by Kleyn in 1944, is an otologic emergency ${ }^{1}$ and in many ways continues to be a mystery. ${ }^{2}$ The widely accepted definition of SSNHL was given by Wilson et al as "a sensorineural hearing loss of at least $30 \mathrm{~dB}$ over three contiguous frequencies on pure tone audiometry (PTA) occurring acutely under 72 hours from initial onset." ${ }^{3}$

Patients of SSNHL tend to delay or postpone their visit to the otologist, owing to the high rates of spontaneous recovery, which can range anywhere between 34 and $67 \%{ }^{4}$ Medical records in the hospitals globally might not have the exact number of these patients, as many of them on their first visit get misdiagnosed as Eustachian Catarrh. However, the incidence of SSNHL has been estimated to be around $8(5-20)$ per 100,000 per year. 5

Steroid therapy, either oral or parenteral, has been the mainstay of treatment of SSNHL for many years now. There have been numerous clinical trials conducted by Parnes, Wilson, Silverstein, Xenellis, and others on the most efficacious route of administration of steroids for the treatment of this condition, 
but there still remains a huge lacuna in the understanding of both, the disease and its treatment. ${ }^{6}$ We present the details of the nonrandomized clinical trial we conducted at our hospital, to compare the effectiveness of intratympanic (IT) steroid therapy alone and combined intravenous-cum-intratympanic (IVIT) steroid therapy in the management of SSNHL.

\section{Materials and Methods}

\section{Study Design}

Nonrandomized clinical trial

\section{Study Period}

August 2013 to May 2015 (21 months)

\section{Sample Size Estimation}

The sample size was calculated using values from the previous studies on SSNHL; Koltsidopoulos et $\mathrm{al}^{7}$ reported that the median improvement in the hearing was $23.12 \mathrm{~dB}$ (interquartile range $[\mathrm{IQR}]=7.18-42.5 \mathrm{~dB}$ ) in the intervention group (patients who received IT as well as systemic steroids) vis-à-vis the control group where the improvement was 16.87 $\mathrm{dB}(\mathrm{IQR}=3.43-35.31 \mathrm{~dB})$ in the control group (patients who received systemic steroids alone). Van Wijck et $\mathrm{al}^{8}$ reported that the mean improvement in hearing was $24.12 \mathrm{~dB}( \pm 12$ $\mathrm{dB}$ ) in the group receiving IT steroids. Based on the values, we hypothesized that there would be a difference in the mean hearing improvement of at least $7 \mathrm{~dB}$ between the two groups:

Intervention group consists of patients receiving both IT and IV steroid injections.

Control group consists of patients receiving IT steroid injections alone.

Using the above values in OpenEpi (software to calculate the sample size for interventional studies), we estimated the sample size to be 23 individuals per group. For both randomized and nonrandomized clinical trials, the method of sample size estimation is same and hence, the sample size for this study was fixed at 23 patients per group. However, in the stipulated study period, we only had 44 patients, who fulfilled our inclusion and exclusion criteria; hence, we included the data of 44 patients in the study. We assigned 23 patients to the Group IT and 21 patients to Group IVIT, based on age, diabetic status, previous history of tuberculosis, and acid peptic disease.

\section{Study Population}

Patients fulfilling the following inclusion and exclusion criteria will be enrolled and will be allowed to participate in the trial.

\section{Inclusion Criteria}

1. Patients should have a HL of $\geq 30 \mathrm{~dB}$ across three contiguous frequencies occurring in less than 3 days.

2. Patients should present to the hospital within 10 days of the onset of the HL.

3. Patients should be older than 18 years of age.

4. Patients who give consent to be part of the trial after understanding the process.

\section{Exclusion Criteria}

1. Patients who do not give their consent to be a part of this trial.

2. Previous history of HL in the same ear.

3. Meniere's disease in the affected ear.

4. History of chronic suppurative otitis media or cholesteatoma in the affected ear.

5. History of otosclerosis.

6. Prior surgery in the affected ear.

7. History of head and neck cancer or radiation therapy.

\section{Methodology}

The protocol followed in the trial is depicted in the form of a flowchart ( - Fig. 1). After the administration of informed consent, the study patients were divided into two groupsIT and IVIT (according to the treatment protocol); patient's choice along with his/her medical fitness for the said therapy (as high dose systemic steroids can have adverse effects in patients with diabetes mellitus, previous history of tuberculosis, acid peptic disease and in old patients) were the factors taken into consideration for grouping, thus justifying the type of clinical trial as nonrandomized.

Patients in Group IVIT were admitted for 5 days and were given Intravenous Methylprednisolone (Solumedrol) on 1st, 2nd, and 3rd days at doses of $1 \mathrm{~g}, 500 \mathrm{mg}$, and $250 \mathrm{mg}$ respectively. Additionally, the patients were administered IT steroid injections (dexamethasone $4 \mathrm{mg} / \mathrm{mL}$ ) on 1st, 3rd, and 5th days. Patients of Group IVIT were monitored for the blood glucose levels, kidney function tests, and lipid profile. Patients in Group IT were admitted for 5 days and were only given IT steroid injections (dexamethasone $4 \mathrm{mg} / \mathrm{mL}$ ) on 1st, 3rd, and 5th days. All the patients were discharged on the 6 th day.

\section{Procedure of Intratympanic Steroid Injection}

Patient was put in supine position with affected ear upwards and the head turned to the opposite side. After confirming an intact tympanic membrane (TM), a four-quadrant local anesthetic infiltration was given (using a mixture of $10 \mathrm{~mL}$ of $2 \%$ Xylocaine, $10 \mathrm{~mL}$ of sterile water, and 10 drops [23-gauge needle] of adrenaline, making a solution of 1:160000 concentration of adrenaline and $1 \%$ xylocaine). An anterosuperior myringotomy was performed and the steroid injection (dexamethasone [4 $\mathrm{mg} / \mathrm{mL}] \quad 0.5-1 \mathrm{~mL}$ ) was given in the posteroinferior quadrant with an insulin syringe using a 26-gauge needle. Patient was kept in the same position for an hour following the procedure and was asked to refrain from swallowing during the said time period.

\section{Outcome Measures}

The impact of steroid therapy on patients with SSNHL was measured objectively with the help of PTA. The improvement in hearing was assessed in terms of decibels gained after the intervention in both the groups and this change was compared using statistical tests.

\section{Statistical Analyses}

Data collected were entered on Microsoft Excel spreadsheet. Simple measures of central tendency and dispersion were 


\section{Group IT (23 Patients of SSNHL)}

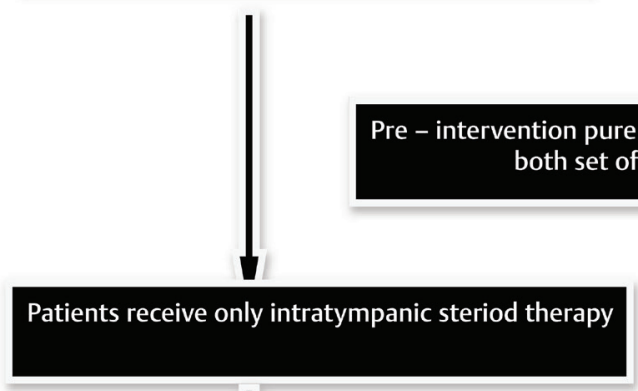

$1^{\text {st }}$ Post - intervention pure tone

audiometry for both set of patients after 10 days after all the injections

\section{Group IVIT (21 Patients of SSNHL)}

Patients receive intratympanic as well as intravenous steriod therapy

$2^{\text {nd }}$ Post - intervention pure tone audiometry after 3 months of all the injections

Fig. 1 Methodology of the study in a flowchart. IVIT, intravenous intratympanic.

used to describe the data initially. Data collected comprised of data for the patients in the intervention group and those in the control group. The groups were mutually exclusive. Hence, to compare mean changes in hearing as assessed by the PTA values, between two groups we used the "Unpaired ' $t$ ' test." The unpaired "t" test is preferred to lend statistical support in this situation. ${ }^{9}$ In addition, within each of the two groups we compared the hearing improvement following intervention-within group, before, and after interventionand to lend statistical support to this change we used "Paired ' $t$ ' test" between the baseline reading and the final reading. In addition, we had two readings in between the baseline reading and the final reading, and in those circumstances, for which we used the repeated measures analysis of variance. ${ }^{10}$

\section{Results}

The present study was conducted among 44 SSNHL patients (31 males and 13 females) with mean age at presentation being $47.43( \pm 14.358)$ years and range between 18 and 77 years.

All the patients presented with a history of HL. Duration of HL ranged from 1 to 10 days with a mean of $6.18( \pm 3.559)$ days, while the median duration of HL was found to be 7 days.
Both ears were affected almost equally, with right ear was affected in 23 patients (52.3\%) and the left ear was affected in 21 patients (47.7\%). Tinnitus, aural fullness, and vertigo were the three additional symptoms that the patients complained of ( - Table 1 ).

Of the 44 patients, 17 patients had a history of smoking tobacco (38.6\%), 15 had diabetes mellitus (34.1\%), while 10 had hypertension (22.7\%). In addition, two patients had hyperlipidemia (4.5\%), two patients gave a history of recent air travel (4.5\%), two patients had a history suggestive of ototoxicity (4.5\%), and one patient had a history of trauma (2.3\%). In 25 (56.8\%) of the patients, Rinne's test was positive, indicating air conduction being better than bone conduction in them. However, in 19 (43.2\%) patients, Rinne's test was false negative, owing to the unilateral profound HL.

Of the 44 patients, 23 patients received IT injections alone (52.3\%), while the remaining 21 patients received combined IT and IV injections (47.7\%). Bone conduction thresholds were assessed at frequencies ranging from 250 to $4,000 \mathrm{~Hz}$, both before and after intervention. The average bone conduction values at baseline were compared with those after the intervention, that is, at 10 days postintervention and at 3 months postintervention. The difference in the means at each of the frequencies was statistically tested using the repeated measures

Table 1 Associated symptoms and their duration

\begin{tabular}{|l|l|l|l|l|}
\hline Associated symptoms & Present & Absent & \multicolumn{3}{|l|}{ Duration of symptoms (in days) } \\
\cline { 4 - 6 } & $n(\%)$ & $n(\%)$ & Mean ( \pm SD) & Median \\
\hline Tinnitus $(n=44)$ & $31(70.5 \%)$ & $13(29.5 \%)$ & $5.37( \pm 3.124)$ & 5 \\
\hline Aural fullness $(n=44)$ & $8(18.2 \%)$ & $36(81.8 \%)$ & $4( \pm 2.878)$ & 3 \\
\hline Vertigo $(n=44)$ & $16(36.4 \%)$ & $28(63.6 \%)$ & $4.17( \pm 2.670)$ & 4 \\
\hline
\end{tabular}

Abbreviation: SD, standard deviation. 
analysis of variance (-Table 2). The results showed that statistically that the intervention (both IT and IVIT) had a significant impact on bone conduction values at all frequencies ( - Fig. 2). PTA was measured by calculating the average of the air conduction values at all the aforementioned frequencies. The mean PTA values were compared between preintervention (IT and IVIT), 10 days postintervention (IT and IVIT), and 3 months post-intervention (IT and IVIT). The improvement in the mean PTA values was tested statistically using the repeated measures analysis of variance and it was found to be statistically significant (-Table 3 ). The mean improvement in PTA after 3 months in IT steroids group was $19.78( \pm 18.918)$ $\mathrm{dB}$ and the mean improvement in PTA after 3 months in IV and IT steroids group was $22.29( \pm 16.147) \mathrm{dB}$.

Based on the PTA, all patients were grouped into five categories (Goodman's Classification) namely, mild HL (25-40 $\mathrm{dB})$, moderate HL (41-55 dB), moderately severe HL (56-70 $\mathrm{dB})$, severe HL (71-90 dB), and profound HL (>90 dB). A majority of the study population had either moderate $(27.3 \%)$ or moderately severe $(27.3 \%)$ or severe $(29.5 \%)$ HL, while a small proportion had mild (2.3\%) or profound HL (13.6\%).
The proportion of people in the five different categories of hearing status changed over time from baseline till 3 months postintervention in both the groups of patients ( - Table 4 ).

On comparing the proportion of patients in each category of HL between the two intervention groups, it was found that there was no statistically significant difference between the two groups, neither at 10 days postintervention nor at 3 months postintervention (-Table $\mathbf{5}$ ).

Siegel's criteria were used to assess recovery in these patients. Final hearing was defined as the pure tone average for each patient, 3 months after intervention while the hearing gain was the difference between the pure tone average at baseline and at 3 months after intervention. Accordingly, the recovery could be complete recovery, partial recovery or no recovery:

- Complete-final PTA better than $25 \mathrm{~dB}$

- Partial-hearing gain exceeding $15 \mathrm{~dB}$ but with final PTA between 25 and $45 \mathrm{~dB}$

- None-hearing gain was less than $10 \mathrm{~dB}$

Of the 44 patients that received the intervention, 11 patients had complete recovery (25\%), 13 patients had partial recovery

Table 2 Mean $( \pm S D)$ bone conduction values-comparison between pre- and postintervention (in both the patient groups)

\begin{tabular}{|l|l|l|l|l|}
\hline Frequency & Preintervention $(\mathrm{dB})$ & $\begin{array}{l}\text { BC at 10 days } \\
\text { postintervention }(\mathrm{dB})\end{array}$ & $\begin{array}{l}\text { BC at } 3 \text { months } \\
\text { postintervention }(\mathrm{dB})\end{array}$ & Statistical significance $^{\mathrm{a}}$ \\
\hline $250 \mathrm{~Hz}$ & $38.64( \pm 9.485)$ & $25.68( \pm 12.463)$ & $21.02( \pm 10.975)$ & $F\left(2_{, 86)}=57.973 p=0.000\right.$ \\
\hline $500 \mathrm{~Hz}$ & $46.36( \pm 9.727)$ & $30.91( \pm 15.336)$ & $25.00( \pm 14.387)$ & $F\left(2_{, 86)}=62.872 p=0.000\right.$ \\
\hline $1,000 \mathrm{~Hz}$ & $54.32( \pm 9.918)$ & $39.20( \pm 17.945)$ & $34.43( \pm 18.684)$ & $F\left(2_{, 86)}=48.655 p=0.000\right.$ \\
\hline $2,000 \mathrm{~Hz}$ & $54.55( \pm 12.239)$ & $40.68( \pm 19.277)$ & $37.39( \pm 20.101)$ & $F\left(2_{, 86)}=41.538 p=0.000\right.$ \\
\hline $4,000 \mathrm{~Hz}$ & $52.39( \pm 13.184)$ & $42.95( \pm 17.298)$ & $40.11( \pm 18.723)$ & $F\left(2_{, 86)}=27.476 p=0.000\right.$ \\
\hline
\end{tabular}

Abbreviations: BC, bone conduction; $\mathrm{dB}$, decibel; SD, standard deviation.

astatistical significance was tested using repeated measures analysis of variance.

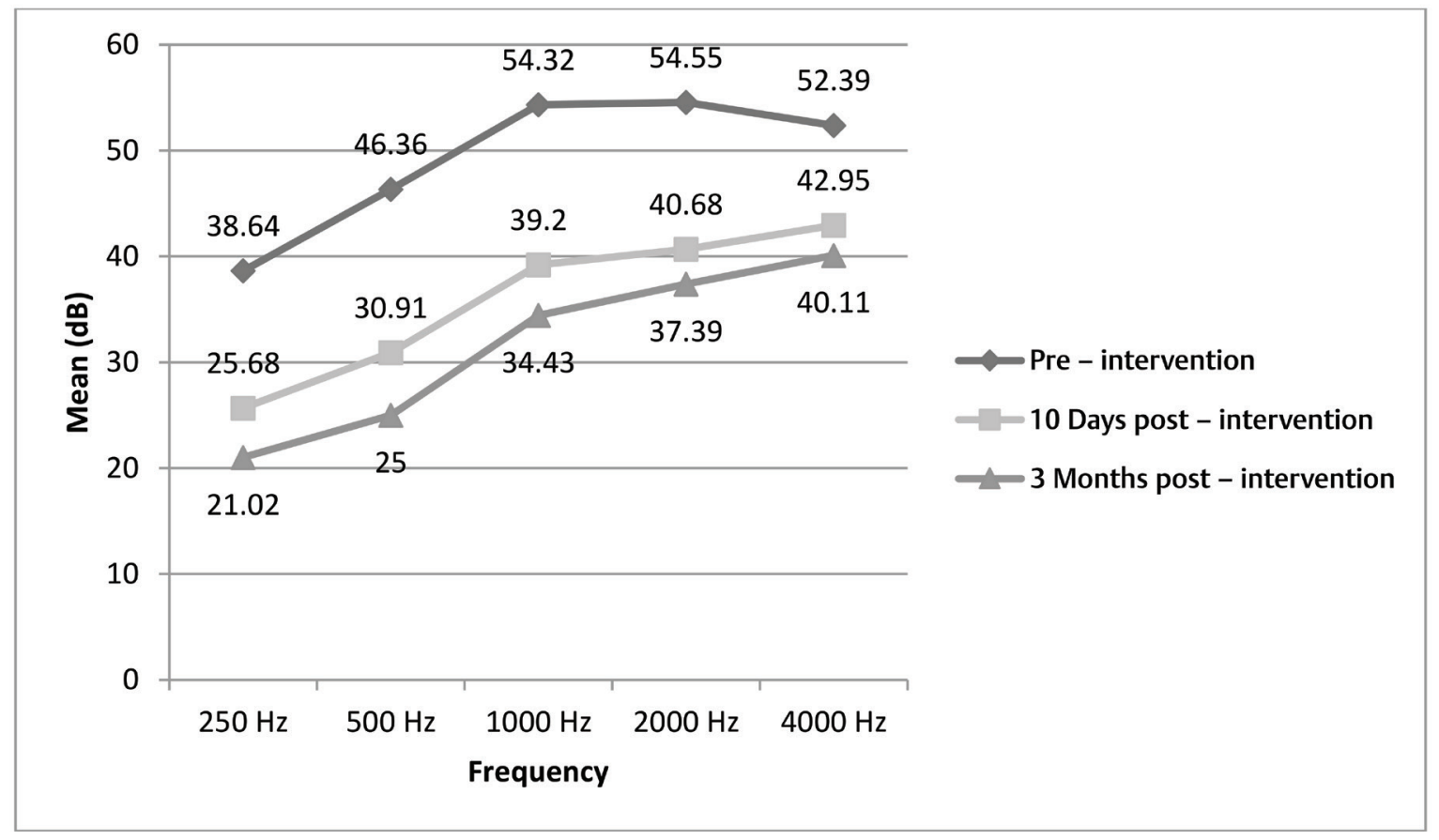

Fig. 2 Mean ( \pm standard deviation) bone conduction values: comparison between pre- and postintervention. 
Table 3 Comparing mean PTA values between preintervention, 10 days postintervention, and 3 months postintervention (in both the patient groups)

\begin{tabular}{|l|l|l|}
\hline Pure tone audiometry & Mean $( \pm$ SD $)$ & Statistical significance \\
\hline Pure tone average at baseline (preintervention) & $67.75( \pm 17.822) \mathrm{dB}$ & \multirow{2}{*}{$F_{(2,86)}=46.912 p=0.000$} \\
\cline { 1 - 2 } Pure tone average at 10 days postintervention & $53.20( \pm 24.737) \mathrm{dB}$ & \\
\cline { 1 - 2 } Pure tone average at 3 months postintervention & $46.77( \pm 25.163) \mathrm{dB}$ & \\
\hline
\end{tabular}

Abbreviations: PTA, pure tone audiometry; SD, standard deviation.

astatistical significance was tested using repeated measures analysis of variance.

Table 4 Proportion of the study population in different categories of hearing loss: Pre- and postintervention comparison (in both the patient groups)

\begin{tabular}{|l|l|l|l|}
\hline Degree of hearing loss & $\begin{array}{l}\text { Baseline (preintervention), } \boldsymbol{n} \\
(\%)\end{array}$ & $\begin{array}{l}\text { 10 Days postintervention, } \boldsymbol{n} \\
(\%)\end{array}$ & $\begin{array}{l}3 \text { Months postintervention, } \\
\boldsymbol{n}(\%)\end{array}$ \\
\hline Mild & $1(2.3 \%)$ & $16(36.4 \%)$ & $22(50.0 \%)$ \\
\hline Moderate & $12(27.3 \%)$ & $9(20.5 \%)$ & $7(15.9 \%)$ \\
\hline Moderately severe & $12(27.3 \%)$ & $7(15.9 \%)$ & $7(15.9 \%)$ \\
\hline Severe & $13(29.5 \%)$ & $8(18.2 \%)$ & $5(11.4 \%)$ \\
\hline Profound & $6(13.6 \%)$ & $4(9.1 \%)$ & $3(6.8 \%)$ \\
\hline Total & $44(100.0 \%)$ & $44(100.0 \%)$ & $44(100.0 \%)$ \\
\hline
\end{tabular}

Table 5 Distribution of the study population by the category of hearing loss and the type of intervention at 10 days and 3 months postintervention (in both the patient groups)

\begin{tabular}{|c|c|c|c|c|c|c|c|}
\hline \multirow[t]{4}{*}{$\begin{array}{l}\text { At } 10 \mathrm{~d} \\
\text { postintervention }\end{array}$} & & $\begin{array}{l}\text { Mild, } n \\
(\%)\end{array}$ & $\begin{array}{l}\text { Moderate, } \\
n(\%)\end{array}$ & $\begin{array}{l}\text { Moderately } \\
\text { severe, } n(\%)\end{array}$ & $\begin{array}{l}\text { Severe, } n \\
(\%)\end{array}$ & $\begin{array}{l}\text { Profound, } \\
n(\%)\end{array}$ & $\begin{array}{l}\text { Statistical } \\
\text { significance }^{a}\end{array}$ \\
\hline & $\begin{array}{l}\text { Intratympanic injec- } \\
\text { tion; } n=23 \text { (52.3\%) }\end{array}$ & 9 (39.1\%) & $2(8.7 \%)$ & $4(17.4 \%)$ & $6(26.1 \%)$ & $2(8.7 \%)$ & \multirow[t]{3}{*}{$\begin{array}{l}\chi^{2}=5.090 ; \mathrm{df} \\
=4 ; p=0.278\end{array}$} \\
\hline & $\begin{array}{l}\text { Intravenous + } \\
\text { intratympanic } \\
\text { injection; } \\
n=21(47.7 \%)\end{array}$ & 7 (33.3\%) & 7 (33.3\%) & $3(14.3 \%)$ & 2 (9.5\%) & 2 (9.5\%) & \\
\hline & $\begin{array}{l}\text { Total; } n=44 \\
(100.0 \%)\end{array}$ & $\begin{array}{l}16 \\
(36.4 \%)\end{array}$ & 9 (20.5\%) & 7 (15.9\%) & $8(18.2 \%)$ & 4 (9.1\%) & \\
\hline \multirow[t]{4}{*}{$\begin{array}{l}\text { At } 3 \text { mo } \\
\text { postintervention }\end{array}$} & & $\begin{array}{l}\text { Mild, } n \\
(\%)\end{array}$ & $\begin{array}{l}\text { Moderate, } \\
n(\%)\end{array}$ & $\begin{array}{l}\text { Moderately } \\
\text { severe, } n(\%)\end{array}$ & $\begin{array}{l}\text { Severe, } n \\
(\%)\end{array}$ & $\begin{array}{l}\text { Profound, } \\
n(\%)\end{array}$ & $\begin{array}{l}\text { Statistical } \\
\text { significance }^{a}\end{array}$ \\
\hline & $\begin{array}{l}\text { Intratympanic } \\
\text { injection; } n=23 \\
(52.3 \%)\end{array}$ & $\begin{array}{l}11 \\
(47.8 \%)\end{array}$ & $2(8.7 \%)$ & $5(21.7 \%)$ & $4(17.4 \%)$ & $1(4.3 \%)$ & \multirow[t]{3}{*}{$\begin{array}{l}\chi^{2}=4.623 \\
\mathrm{df}=4 \\
p=0.328\end{array}$} \\
\hline & $\begin{array}{l}\text { Intravenous + } \\
\text { intratympanic } \\
\text { injection; } n=21 \\
(47.7 \%)\end{array}$ & $\begin{array}{l}11 \\
(52.4 \%)\end{array}$ & 5 (23.8\%) & 2 (9.5\%) & 1 (4.8\%) & 2 (9.5\%) & \\
\hline & $\begin{array}{l}\text { Total } \\
n=44(100.0 \%)\end{array}$ & $\begin{array}{l}22 \\
(50.0 \%)\end{array}$ & 7 (15.9\%) & 7 (15.9\%) & $5(11.4 \%)$ & $3(6.8 \%)$ & \\
\hline
\end{tabular}

${ }^{\text {a }}$ Statistical significance was tested using chi-squared analysis.

(29.5\%), and 20 patients had no recovery (45.5\%). - Table 6 shows the proportion of people that recovered (either fully or partially) and did not recover in the two intervention groups. Statistically, there was no difference between the intervention groups with respect to the status of recovery.

\section{Discussion}

SSNHL is a life-altering disorder for the patient and it definitely poses a bitter challenge for the otorhinolaryngologists. ${ }^{11}$
The rapidity with which the condition progresses can be quite devastating to the patient. The most important theories that have been hypothesized in the pathogenesis of this condition are viral infection, vascular compromise, intracochlear membrane rupture, and autoimmune inner ear disease. ${ }^{12}$

SSNHL falls within the spectrum of idiopathic acute auditory and vestibular dysfunction, being at the auditory extreme with sudden deafness associated with mild, brief, and transient vestibular episode, if any..$^{13}$ The clinical picture 
Table 6 Association between the type of intervention and status of recovery

\begin{tabular}{|l|l|l|l|l|l|}
\hline & $\begin{array}{l}\text { No recovery, } \\
n(\%)\end{array}$ & $\begin{array}{l}\text { Partial recovery, } \\
n(\%)\end{array}$ & $\begin{array}{l}\text { Complete } \\
\text { recovery, } n(\%)\end{array}$ & Total, $n$ (\%) & $\begin{array}{l}\text { Statistical } \\
\text { significance }\end{array}$ \\
\hline $\begin{array}{l}\text { Intratympanic (IT) } \\
\text { injection }\end{array}$ & $11(47.8 \%)$ & $6(26.1 \%)$ & $6(26.1 \%)$ & $23(52.3 \%)$ & $\begin{array}{l}\chi^{2}=0.277 ; \mathrm{df}=2 ; \\
p=0.870\end{array}$ \\
\hline $\begin{array}{l}\text { Intravenous + } \\
\text { intratympanic (IVIT) } \\
\text { injection }\end{array}$ & $9(42.9 \%)$ & $7(33.3 \%)$ & $5(23.8 \%)$ & $n=44(100.0 \%)$ & \\
\hline Total & $20(45.5 \%)$ & $13(29.5 \%)$ & $11(25.0 \%)$ & $n)$ \\
\hline
\end{tabular}

a Statistical significance was tested using chi-squared analysis.

of SSNHL consists of acute ( $<3$ days) onset HL, which is almost always unilateral. Only $2 \%$ of the patients show bilateral presentation. ${ }^{6}$ The median onset of age is from 40 to 54 years with no sex predilection. Patients may present with a symptom of HL on awakening from sleep or hearing a "pop" in the affected ear just prior to HL. ${ }^{6}$ Hearing loss can be either an acute loss from a state of normal hearing or it can be in the form of an acute deterioration from a pre-existing $\mathrm{HL}$, which may or may not be documented. In most of these cases, there is no premorbid audiogram available for comparison, and the HL is usually considered in comparison with that of the healthy ear. ${ }^{14}$ SSNHL can affect loudness or clarity or both; it can affect all the frequencies equally or only the higher or lower frequencies, the severity of which may vary. Worse the $\mathrm{HL}$, the poorer is its prognosis and the greater is the urgency for early treatment. ${ }^{13}$ Vijayendra et al showed that around $70 \%$ of SSNHL patients complain of vertigo, ${ }^{1}$ and it is considered to be one of the bad prognostic factors. It has been seen that in only $~ 5 \%$ of patients the cause behind $\mathrm{HL}$ is elicited, ${ }^{15}$ and patients usually end up having several investigations done ${ }^{16}$; however, the percentage of positive reports, affecting the prognosis or the management of the condition is very low, when weighed against the cost incurred in the evaluation. ${ }^{17}$

A wide range of treatment options have been applied for the management of SSNHL with several varied hypotheses for each, such as, systemic steroids, vasodilators, carbogen, anticoagulants, antivirals, plasma expanders, diuretics, Gingko Biloba, and antioxidants. ${ }^{18}$ According to Clinical Practice Guideline for Sudden Hearing Loss, corticosteroids are to be offered as initial therapy to the patients with SSNHL. ${ }^{19}$ However, there is no standard protocol as on date for the dose or the regimen of steroid therapy. Different routes of administration for the steroids have been tried and none of them have been quoted to be the single most beneficial or efficacious route, paving way for a paradigm shift toward combination therapies, that is, combining two or more different routes of administration for better rates of recovery. ${ }^{20}$ The different routes in which steroids can be administered in SSNHL are oral, intravenous, and intratympanic. ${ }^{6}$

Steroids have been found to increase the cochlear blood flow, ${ }^{21}$ improve the function of vascular stria, ${ }^{22}$ reduce inflammation secondary to labyrinthitis, ${ }^{23}$ and improve ion homeostasis necessary for cochlear function. ${ }^{24}$ Both methylprednisolone and dexamethasone have been used for IT steroid therapy in different studies. However, for our trial, we preferred dexamethasone $(4 \mathrm{mg} / \mathrm{mL})$ over methylprednisolone for IT route, as the former is more potent, longer acting ${ }^{8,25}$ and has also been known to have a good round window diffusion. ${ }^{26}$

In our study of 44 patients, the mean PTA at baseline was $67.75 \mathrm{~dB}( \pm 17.822)$. In Group IT, the mean PTA at 10 days postintervention was $55.65 \mathrm{~dB}( \pm 25.26)$ and $50.52 \mathrm{~dB}( \pm 24.47)$ in Group IVIT. At 3 months postintervention, the mean PTA in Group IT was $49.48 \mathrm{~dB}( \pm 25.172)$ and $43.81 \mathrm{~dB}( \pm 25.430)$ in Group IVIT. In the study conducted by Hunchaisri et al, the pretreatment PTA was $65.8 \pm 20.4 \mathrm{~dB}$ and the posttreatment PTA was $48.3 \pm 17.5 \mathrm{~dB}$ in the improvement group, after IT dexamethasone injections. ${ }^{26}$ The mean improvement in PTA after 3 months in Group IT was $19.78( \pm 18.918) \mathrm{dB}$ and in Group IVIT, the same was $22.29( \pm 16.147) \mathrm{dB}$. Koltsidopoulos et al showed a median improvement in the hearing of 23.12 $\mathrm{dB}(\mathrm{IQR}=7.18-42.5 \mathrm{~dB})$ in the intervention group (IT steroids and systemic steroids $)$ and $16.87 \mathrm{~dB}(\mathrm{IQR}=3.43-35.31 \mathrm{~dB})$ in the control group (systemic steroids alone). ${ }^{7}$

In our study, we found no statistically significant difference in the effectiveness between IT steroid therapy alone and combined IVIT steroid therapy, which was measured in terms of hearing improvement after the intervention.

\section{Conclusion}

After drawing comparisons between the figures from our study and the already existing literature on this topic, it is therefore safe to conclude that both IT and IVIT steroid therapies are efficacious in the management of SSNHL. Since there is no statistically significant difference in the effectiveness of the above-mentioned modalities, the use of IT steroids alone is recommended for the management of SSNHL.

\section{Ethical Approval}

The research involves human participants and all the procedures performed in the study involving human participants were in accordance with the ethical standards of the institutional and/or national research committee and with the 1964 Helsinki declaration and its later amendments or comparable ethical standards.

\section{Informed Consent}

Informed consent was obtained from all individual participants included in the study.

\section{Conflict of Interest}

None declared. 


\section{Acknowledgments}

The authors would like to thank all the patients, who consented to be a part of the study, colleagues, and the support staff from hospital, who made this study possible.

\section{References}

1 Vijayendra H, Buggaveeti G, Parikh B, Sangitha R. Sudden sensorineural hearing loss: an otologic emergency. Indian J. Otolaryngol Head Neck Surg 2012;64(1):1-4

2 Kleyn AD. Sudden complete or partial loss of function of the octavus-system in apparently normal persons. Acta Otolaryngol 1944;32(5-6):407-429

3 Wilson WR, Byl FM, Laird N. The efficacy of steroids in the treatment of idiopathic sudden hearing loss. A double-blind clinical study. Arch Otolaryngol 1980;106(12):772-776

4 Schuknecht HF, Donovan ED. The pathology of idiopathic sudden sensorineural hearing loss. Arch Otorhinolaryngol 1986;243(1):1-15

5 Byl FM Jr. Sudden hearing loss: eight years' experience and suggested prognostic table. Laryngoscope 1984;94(5 Pt 1):647-661

6 QuinnFB, Ryan MW, Kharodwala M, Makishima T. Sudden Sensorineural Hearing Loss and Intratympanic Steroids. Paper presented at: Grand Rounds Presentation, UTMB, Dept. Of Otolaryngology; June 14, 2006

7 Koltsidopoulos P, Bibas A, Sismanis A, Tzonou A, Seggas I. Intratympanic and systemic steroids for sudden hearing loss. Otol Neurotol 2013;34(4):771-776

8 Van Wijck F, Staecker H, Lefebvre PP. Topical steroid therapy using the Silverstein Microwick in sudden sensorineural hearing loss after failure of conventional treatment. Acta Otolaryngol 2007;127(10):1012-1017

9 Patrikar SR. Hypothesis testing: the difference between two population means. In: Bhalwar R, ed. Text Book of Public Health and Community Medicine. Department of Community Medicine. Pune, India; Armed Forces Medical College, Pune in collaboration with World Health Organization India office; 2009:243

10 Patrikar SR. Which statistical procedures to use depending upon exposure and outcome variable? In: Bhalwar R ed. Text Book of Public Health and Community Medicine. Department of Community Medicine, Armed Forces Medical College, Pune in collaboration with World Health Organization, India office; 2009:274

11 Ferri E, Frisina A, Fasson A.C, Armato, E, Spinato, G, Amadori M. Intratympanic steroid treatment for idiopathic sudden sensorineural hearing loss after failure of intravenous therapy. ISRN Otolaryngol; 2012;2012:64271
12 Lin SW, Lin YS, Weng SF, Chou CW. Risk of developing sudden sensorineural hearing loss in diabetic patients: a population-based cohort study. Otol Neurotol 2012;33(9):1482-1488

13 Massachusetts Eye and Ear. [Online]. Available at:http://www. masseyeandear.org/for-patients/patient-guide/patient-education/diseases-and-conditions/sudden-deafness/. Accessed April 11, 2017

14 Gianoli GJ, Li JC. Transtympanic steroids for treatment of sudden hearing loss. Otolaryngol Head Neck Surg 2001;125(3):142-146

15 Rauch SD, Halpin CF, Antonelli PJ, etal.Oral vs intratympanic corticosteroid therapy for idiopathic sudden sensorineural hearing loss: a randomized trial. JAMA 2011;305(20):2071-2079

16 Arastou S, Tajedini A, Borghei P. Combined intratympanic and systemic steroid therapy for poor-prognosis sudden sensorineural hearing loss. Iran J Otorhinolaryngol 2013;25(70):23-28

17 Heman-Ackah SE, Jabbour N, Huang TC. Asymmetric sudden sensorineural hearing loss: is all this testing necessary? J Otolaryngol Head Neck Surg 2010;39(5):486-490

18 Chandrasekhar SS, Saunders JE. 2008 and 2011). Sudden Sensorineural Hearing Loss: An Otologic Emergency? AAO-HNSF AcademyU ${ }^{\circledR}$ online classroom.

19 Stachler RJ, Chandrasekhar SS, Archer SM, et al; American Academy of Otolaryngology-Head and Neck Surgery. Clinical practice guideline: sudden hearing loss. Otolaryngol Head Neck Surg 2012;146(3 Suppl):S1-S35

20 Kim YH, Park KT, Choi BY, et al. Early combination treatment with intratympanic steroid injection in severe to profound sudden sensorineural hearing loss improves speech discrimination performance. Eur Arch Otorhinolaryngol 2012;269(10):2173-2178

21 Stokroos RJ, Albers FW, Schirm J. The etiology of idiopathic sudden sensorineural hearing loss. Experimental herpes simplex virus infection of the inner ear. Am J Otol 1998;19(4):447-452

22 Lamm K, Arnold W. The effect of prednisolone and non-steroidal anti-inflammatory agents on the normal and noise-damaged guinea pig inner ear. Hear Res 1998;115(1-2):149-161

23 Rarey KE, Luttge WG. Presence of type I and type II/IB receptors for adrenocorticosteroid hormones in the inner ear. Hear Res 1989;41(2-3):217-221

24 Yilmaz I, Yilmazer C, Erkan AN, Aslan SG, Ozluoglu LN. Intratympanic dexamethasone injection effects on transient-evoked otoacoustic emission. Am J Otolaryngol 2005;26(2):113-117

25 Kopke RD, Hoffer ME, Wester D, O'Leary MJ, Jackson RL. Targeted topical steroid therapy in sudden sensorineural hearing loss. Otol Neurotol 2001;22(4):475-479

26 Hunchaisri N, Chantapant S, Srinangyam N. Intratympanic dexamethasone for refractory sudden sensorineural hearing loss. J Med Assoc Thai 2010;93(12):1406-1414 